\title{
Patients' Knowledge and Perception on Anaesthesiologist And Anaesthesia
}

Suhaila Binti Nanyan ${ }^{1}$, Mohamad Fariz Bin Johari², Mohamad Nazrin Bin Holid², Usamah Bin Othman ${ }^{2}$

${ }^{1}$ Department of Anaesthesiology and Intensive Care, Kulliyyah of Medicine, International Islamic University Malaysia

${ }^{2}$ Kulliyyah of Medicine, International Islamic University Malaysia

Presenter: Suhaila Binti Nanyan

Introduction: Anaesthesiologists play vital roles in perioperative patients' care and chronic pain management. However, not many patients are aware of therole of anaesthesiologists. We aimed to measure the level of patients' knowledge regarding the role of anaesthesiologist and anaesthesia. Materials and Methods: This was a single-centred, questionnaire-based cross sectional study. The selfadministered questionnaire was divided into three parts that includes, i) sociodemographic characteristics, ii) knowledge regarding role of anaesthesiologist, iii) knowledge of anaesthesia. Respondents were selected among patients attending several specialist clinics at the International Islamic University Malaysia Medical Centre (IIUM MC). Results: Almost 64\% of the selected patients had previous experience of anaesthesia. Majority of the patients (78\%) knew that anaesthesiologist is a medical qualified doctor, but only $52.5 \%$ of them knew the role of anaesthesiologist in operation theatre. Fifty eight percents of patients realized the fact that anaesthesiologist is primarily responsible to ensures the well-being during operation, $45.1 \%$ knew the involvement of anaesthesiologist in case of emergency and in the intensive care unit, $46.7 \%$ in managing obstetrics pain, $39.3 \%$ in long-standing pain, $52.5 \%$ on the issue of pre-operative visits and post-operative recovery. Besides that, $72.1 \%$ were well-informed regarding fasting before operation, 59.8\% realized that smoking may affect the anaesthesia and surgery, $86.1 \%$ knew where anaesthesia will be administered, $66.4 \%$ and $62.3 \%$ of respondents knew regarding the general and regional types of anaesthesia respectively. Seventy three percents of patients realize how general anaesthesia will be administered. Lastly, only $54.9 \%$ of patients had some knowledge regarding complications of anaesthesia. There were also not much impacts of previous exposure of anaesthesia on the level of their knowledge. Conclusion: Patients' knowledge regarding the role of anaesthesiologist and anaesthesia were average and variable. 